\title{
Keys to Success in Conducting Science Project: A Case Study of High School Winner from the Science Project Contest in Thailand
}

\author{
Nunthicha Bunlaead ${ }^{1}$, Narisara Peungposop ${ }^{2}$ and Wilailak Langka ${ }^{3}$ \\ ${ }^{1}$ Master Degree Students, Division of Educational Research and Statistics, \\ Faculty of Education, Srinakharinwirot University, Thailand. \\ ${ }^{2}$ Behavioral Science Research Institute, Srinakharinwirot University, Thailand. \\ ${ }^{3}$ Department of Educational Measurement and Research, Faculty of Education, \\ Srinakharinwirot University, Thailand.
}

\begin{abstract}
The research aimed to study the process and key factors to success of conducting the school science project that won the science project contest at country level held by the Science Society of Thailand under the Patronage of His Majesty the King. The qualitative research was designed. Data were collected using in-depth interview. The case study was the school winner four consecutive years was located in Northern Thailand. The case and participants were selected by criterion purposive sampling. The participants included the school director, the project advisors, and the students who attended the projects. The Semi-structured interview and content analysis were employed to collect and analyze data, respectively. The findings showed that the process of conducting the science project was divided into three phases. The first phase was pre-operation: in this phase, the advisors used strategies to encourage students to observe their daily life problems. The second phase was an operation: during this phase, the students conducted an experiment to solve problems and made the report. The last phase was the project completion: students presented their projects, evaluated the projects, and then prepared for the contest. The keys to success in conducting science project were based on scientific knowledge and competitive experience. Research also found that the keys to success were a) the sacrifice of advisers, $b$ ) need for achievement and self-discipline of students, and c) support from school directors
\end{abstract}

Keywords: science project, keys to success, teaching the Project, qualitative research

\section{Introduction}

Science is one of the foundations which is important to a country to develop and progress in every field together with establishment of the youth populations' positive perspectives. In the present time, many senior high schools have encouraged their students to apply the knowledge they learn with daily tasks systematically. Procedures are standardized and reasonable based on the knowledge of students in each level or students' interests. This has given opportunities to students to study and experience by doing assigned projects as a part of their studies such as projects in Science and Mathematics subjects.

Science projects are activities that improve students in term of scientific procedures which encourage them to seek out for more knowledge, make them think by themselves, know how to proceed, and know how to solve problems. From such activities, they have led the students to some doubts which they have to try to figure these doubts of theirs out by themselves first and try to plan their systemically working process. When students' projects become successful, the students will have learnt how to apply their knowledge and procedures of any work themselves. 
The scientific project competitions set up under the control of The Science Society of Thailand under the Patronage of His Majesty the King has 2 levels - Junior high school and Senior high school. In each level is divided into 3 branches which are Physical Science, Biology, and Applied Science. All projects from 6 regional stations will be competing one another in their regions which the competition is set up every year to select the best projects in each region to join the national round for win the gold medal. The winner of the gold medal in the national round from senior high school completion will be competing the last round called "Best of the Best". The winner of this round will be conferred the prize by Her Royal Highness Princess Maha Chakri Sirindhorn in the Science and technology conference of Thailand and will be given an honour to join the international science project competition. (The Science Society of Thailand under the Patronage of His Majesty the King : 2014)

With all these reasons, the researcher is interested in studying that the winning schools that have won the prizes, what process of making projects they have done and which conditions they have done to become successful.

\section{Research Objectives}

2.1 To study the procedures of making science projects of the school that have won the prizes from The Science Society of Thailand under the Patronage of His Majesty the King.

2.2 To study the key to success in doing their winning projects from The Science Society of Thailand under the Patronage of His Majesty the King.

\section{Literature Review}

Institute for the Promotion of Teaching Science and Technology (1999) has mentioned that the science projects are for training the students to create their own thinking process through their knowledge, be expertise, and be confident to bring scientific methods to apply and solve the problems occurred and seek out for more knowledge themselves. Other values of science projects are as following 1. Create responsibility trait in researching for knowledge themselves 2. Give the chances to every student to improve and show his/her talents 3. Give the chances to research and acquire more knowledge by themselves 4 . Students who have special talents have their opportunities to show out their talents. 5. Stimulate the interests in studying science and working in science field in the future. 6 . Students get to use their free times creatively and beneficially 7 . Students create the friendship among other students and relations between students and teachers. 8. Create relations between schools and communities. Schools have their chances to propagate the knowledge and technology to communities which impulse the interests in science and technology.

Sukda Satapornwajana (1997) has mentioned that "Studying of the procedures of creating the winning science projects of Senior high schools from The Science Society of Thailand under the Patronage of His Majesty the King aims to learn steps of the science projects and how to aluminate the problems of 6 winning schools. The directors of those schools, teachers who are in charge of supervising the projects and some experts have been interviewed and they have given their points of views as following 1 . The objectives are assigned to the science department of each school and the department needs to perform to achieve those objectives substantially. The set objectives are created by the relevant people - participants of the projects and teachers in the science department to help plan the science projects, select workers who would be involved in the projects by their qualifications and fields of their expertise, prepare the buildings and places, prepare intermediaries, tools and equipment, prepare the budgets, advertise the projects, and contact the related organisations. 2.The procedures are divided into think and select the thesis/ topics, plan the studies and performance during the process of making projects, take actions and make progress in projects, writing the report essays, and show out the projects. The supports of the creation of the science projects, the related persons who have supported and encouraged are School directors, Advisors (teachers) of the projects, skilful students, and parents of those participants (students), and experts in the areas. 3. There are evaluations of all science projects after. 
Pitak Chiangnok (1997) the roles of school directors as following 1. Support teachers and students in procedures of the science projects by providing them the suitable budgets, and tools. 2. Encourage the activities for students to show out their projects. 3. Understand that they need to support teacher and student need to seek out the knowledge outside classes and spend some extra times outside. So, the school directors should support them and make them spend time outside efficiently.

Pradit and Naphatsorn Laonet (2009) Teachers have their roles in advising their students by helping them think, plan and design the experiment, set up the variables, design the checking process or design the inventions, researching the information and knowledge related with the equipment and procedures of the projects, taking care and following with the experiments, going out for surveying and making the inventions closely with students, and also looking after the writing report procedures. The most important thing is the advisors (teachers) need to ask questions to students or have students come up with questions on their own to impulse their interests and enthusiasm in creating procedures of the projects constantly.

Sukunlaya Khumphet (2000) The study of conditions and problems in doing the science projects of the Junior high students in Phetchaburi. Problems found are critical. From the interviews of the comments from teachers and students, the problems are 1. Teachers are not expert enough in supervising students as the lack of knowledge in some fields. 2. Students cannot think and select their suitable topics of their science projects. They are lack of some knowledge in proceeding the projects, cannot get along with other students, and receive less supports from their parents. 3. Not enough budgets supporting the science projects and lack of suitable places for doing their science projects.

\section{Methodology}

\subsection{Research Design}

The researcher has proceeded the research by using quality research in a case by randomly selecting the sample for the case which is a big Junior and Senior high school in the North of Thailand are chosen because they have won the 6th national prize of The Science Society of Thailand under the Patronage of His Majesty the King with 4 years and joined the International science project contest-receiving the prize The Intel International Science and Engineering Fair (Intel ISEF) which is considered to be the prize of honour that has made Thai school and Thailand become internationally famous.

\subsection{Key Informants}

- One school director

- Two project advisors

- Two groups of students who attended the projects

\subsection{Instruments}

There are 2 types of tools used with this research

a. Observation format created to record the regular activities of the chosen school and record all actions and attitudes of the interviewees

b. 2 types of Interview forms for school director, advisors and participating students which have the contents as following

Sample questions for the director of the chosen school

- Which ways do you provide and support advisors and students?

- What are factors that you think that make the project become successful? Sample questions for advisors and students

- How do you proceed the winning project, what procedures and which step is the most important?

- What are conditions that make the project become successful? 


\subsection{Data Collection}

The researcher has gathered the data through the interviews of people who are related to the winning project of the chosen school.

The procedures are as following 1.The researcher has studied all related references and related researches to the winning science project. The factors encourage the success of this research are related people and quality analysis of the sample school to separate types of questions of the research and plan out the analysis in order to acquire the correct answers. 2.The researcher has studied other factors which may affect this success of the winning science project such as how to travel to school, which sector is in charge of this school, which size of this school, how many students, teachers and other employees, and which organizations that support the school. 3.Contact the sample school to propose the objectives and intend of the researcher after planning out all research procedures already. 4. Preparing before going to the school by planning out the paths of all performances such as prepare the equipment, camera, recording tool, plan where to stay, and how to travel there.

\subsection{Data Analysis}

According to this research is quality research, the researcher has divided the procedures into 2 steps as following

1. Recheck the data after the interviews and the voice records to guarantee that these data are able to be used by checking through data triangulation and mythological triangulation to reassure the quality of data and completely collected data.

2. Analyze the data and gather information by recording the voices then after coming back to interpret those data carefully again then writing the information down. From the interviewed contents by content analysis. It can be concluded the overall information that the research needs.

\section{Result}

The results are divided into 3 parts 1 . Presentation part presents about the winning science project from The Science Society of Thailand under the Patronage of His Majesty the King 2.Presentation of the procedures of the winning science project 3.Key to success in doing the science projects which has the contents as following

\section{Part 1 The Roles of The winning school}

As the chosen school is the big junior and senior high school under the control of the Department of General Education under the government. It is one of schools in the northern part of Thailand which operates the classes for junior and senior high school students. It has 2,800 students including 138 teachers and employees and has 72 classes. Junior high students which 12 classes are 3 classes for the special science and math program, 1 class is Mini English Program, and 8 classes for general students. For senior high student; 12 classes are 1 class for the Technology-Math-environmental. 5 Special class in science and English is encouraged by external organizations and 6 general classes are provided the study of languages, All students have to study IS (independent Study) through creating the science projects before their graduations. This school has passed the science project competitions such as from The Science Society of Thailand under the Patronage of His Majesty the King. The winning science projects have joined 'Best of the Best' from year 2014-2017 and also they got selected to be representatives of Thailand for The Intel International Science and Engineering Fair (Intel ISEF). From this fair, they got Best of category in animal science, First place special award the scientific research society of sigma XI and European Union for young Scientists in 2015, Second place category in animal science and First place special award the scientific research society of sigma XI in 2016 , and so on.

\section{Part 2. The procedures of the science projects of the winning school from The Science Society of Thailand under the Patronage of His Majesty the King.}

The procedures of the winning science project has been divided into 3 sections such as before the procedures, during the procedures, and after the procedures which each section is related to the process of work as following 


\subsection{Before the procedures}

The start of the winning science project is the most crucial thing. If the start is good, it seems like the participants of this science will have won half way of their goal already. It contains 3 activities which are planning the foundation of the project with IS (Independent Study) by searching the topic thesis of the science project and design the experiment.

The Foundation with IS (Independent Study) advisors are leaders for the start by encouraging the IS in the class. Junior and Senior high school students have to study this subject Therefore, every student needs to know the procedures of doing a project. Teachers who teach IS classes use the scientific procedures as the cores of the study combining with other contents that students already need to study in their regular topics for each field study such as for Math-English students, they will do IS that concentrates on mathematics with English or Science-Math and Technology students, their studying environment mainly focuses on scientific procedures and the contents studied are about the environments etc. Furthermore, teachers who teach the IS subject have integrated other lessons from other subjects which is the teaching technique that does not make students feel bored of the subject. Also, students follow and try to think following what teachers are teaching them as mentioned by teachers

"Scientific methods, we do not only teach them the contents of the studies. Techniques we use to teach them is STEM. After we finish the teachings. We always ask our students, how they will use what they have learnt today and apply this knowledge with their daily lives."

(An advisor of the project 1/ August 19th 2017)

Searching for thesis topic of a project in order to acquire the thesis topic of a science project, advisors have used various approaches by specifying the boundary of a thesis topic of each group of students- different classes, different approaches by 1 . The supportive funds 2 . Going to observe the real areas and 3. Continuing on the topics of some old projects. This school is a provincial school which the area riches in jungles and trees. Parents of students have several occupations. This is considered as the advantages for looking for thesis topics or going on school trips to significant place. Advisors focus on taking their students going in field trips, studying about local people's lives in order to motivate their students to generating problem topics from their surroundings. This helps the development of the projects become easier. So, the advisors mention that

"We set up the camps which is integrated with the scientific methods. The ways students acquire their thesis topics, come up with their hypotheses, topics of problems, and how to research related information."

(An advisor of the project 2/ October 2nd 2017)

Experimental design this step, advisors of the projects will advise their students what and they need to plan on their experiments. Advisors have their students present their topic problems or the topics they are interested in. Then, asking questions to students so that they can generate their thoughts of what are problems occurred, how to eliminate those problems, what tools and materials are needed in the project etc. When students has done their researches more on their thesis topics, advisors can generate more questions asked for them in order to initiate something new in students' minds. The important thing is advisors have to pretend that if they were students, how they would think and find ways to figure out their problems and how much they would think deeply about their problems to understand how their students feel towards the problems. This will motivate the student to dedicate themselves and do their best.

"Design the experiment, we have recommended our students to do their experiments and pretended ourselves like kids again to understand how far our students can think and what we should ask them to initiate their further thinking."

\subsection{During Procedures of Projects}

(An advisor of the project 1/ August 19th 2017)

The Experiment part is the most important part because advisors need to advice their students closely, motivate the working process and help solve the problems happened. For example: When experiments have gone wrongly from what students have expected, advisors will ask their students why this mistakes happened, what reactions made them occur, can we use something else for the experiments instead, and what should we use then 
have students dig deeper for more information etc. During the experimental procedures, students should take pictures or if there are a lot of continuous changes, they should record the videos. This procedure always occurs many problems. Students need to be patient to keep up with their experimental results and search for additional information. The most important thing is the encouragement from their families and their advisors. One group of student say

"Our advisor helps us a lot, always give advices. Sometimes, blaming us but our advisor is the person who keeps pushing us because we are pretty inert in working and have lack of enthusiasm. Recommendations of our advisor are so good. They like god words for us."

(Student from group $1 /$ October 2nd 2017)

Presenting projects clearly the projects will be finished when the reports have been made completelywritten forms of Resources and the importance, references, procedures, conclusions and disputations of the projects need to be completed. Moreover, from the statistic reports of the experiments, all numbers need to be correct. The ways to write down the experimental results have to relate to reasons of the projects or relatedly previous researches done before. Also, they need to relate theories guaranteed those topics done. This will make readers who read projects' reports interpret things more easily and can see the overall pictures of projects. If the contents are clear, this increases the chances that the projects with outstanding reports will overcome other projects as the advisors say

"The reports writing have shown all knowledge the participants in projects have learnt in chapter 2 of projects that what the participants of the projects have done are the imitation of others' projects or not, when they have done their projects. What are results happened or how the results and the projects are better than other people's projects. How topics and results relate to existing theories and science field is applied."

(An advisor of the project 2/ October 2nd 2017)

\subsection{Preparing students before the competitions}

When the projects are finished, each class has a different style of a presentation which will be evaluated by teachers from science department. They evaluate from the interestingness, scientific methods used, contents, further development of the projects. Then, they give comments about the projects. If there are any interesting projects that capture teachers' attention. They will encourage the students on those chosen projects to make more progress for the science project competitions. To enroll science projects for the competitions, the contents in reports of projects have to be completed and recheck the experiments' procedures thoroughly in order to capture other people's attention successfully. Moreover, if further development can be applied into making products or inventions that can be useful for businesses. Those projects would capture interests of others so much. Making the outlines of the projects is also important; contents need to be brief and easily to interpret, pictures need to be suitably beautiful and clear. Before the competition, students should practice their presentations. Advisors will ask them several questions in many ankles to train them to think, answer and arrange the contents in their minds. Then practicing presentations within the give amount of time. One group of students say

"We need to make the complete report first, other groups' reports are thick but ours is thin. We have concluded everything that readers need to understand...mostly cores of the project from researches that are concluded into our own language. However, they need to get the main and correct ideas."

(Student from group 2/ October 2nd 2017)

\section{Part 3 Key to success in making science projects}

From the study, the researcher has found that science projects will become successful, it is not only because of the participants of the projects, but also because of implement of thoughts of supporters and procedures derive the success.

3.1 Important people Researching researches has shown people who have influence on the success of science projects are advisors, students, school director, and parents.

Important persons are advisors: Advisors are the main enforcement to derive the success of the science projects. If students are interested, talented, or are ambitious to achieve something but have lack of advices from 
advisors. They will not become successful until the competitive rounds. As advisors are like leaders of students. Besides, giving advices, advisors also encourage, love and sacrifice for students. Advisors' words are motivation words for students making their dreams become true. One advisor says

"One problem is we have the motivation to do the projects but someone who is going to guide us cannot answer our questions. Students' dreams will be gone. For me, it's the same... We have all answers but they cannot be continued. There is no leader to guide and say how far we have come and how should we continue. If advisors can tell us what we have to add."

(An advisor of the project 1/ August 19th 2017)

Teachers who truly possess teacher souls nowadays, other than teaching as the main part

for teachers, teachers also have other jobs in charge that they have to be responsible for. For project advisors, taking care of students who participate in doing projects is their additional job. Therefore, advisors need to sacrifice their personal times to take care of students and also have mercy and love for them like their own children or their own nephews or nieces. As from one of project advisors says and what students tells about their feelings towards their advisor.

"When I see the kids, I am the one who gives them chances. I see that students have limit of their opportunities but if there is a person who helps them train and experience. They will be more experienced. That's why I'll keep doing this."

(An advisor of the project 1/ August 19th 2017)

"Teacher A is a beloved teacher of ours. When he was very angry, he still wanted to help us.

He told teacher B to come to help us."

(Student from group 1/ October 2nd 2017)

Characteristics of advisors of the projects Advisors should be kind and be ambitious to acquire more knowledge. They should open up themselves for learning new things always and look at more examples of other science projects to find some strengths of those projects and apply with their own fields of studies. Advisors need to be a kind of person who are ready to sacrifice their personal time and money sometimes. The most important thing is they need to love and take good care of their students as advisors says

"There is implement of happiness inside...getting to learn new things to improve myself...feel happy with teaching students who are doing their science projects to learn new things about science."

(An advisor of the project 2/ October 2nd 2017)

Ambitious Students: students are one of most important groups of people. If they love science and ambitious to know the answers, try to find them, bear with obstacles, and be responsible to their duties.

"Students need to be alerted, always questions things, and want to solve problems on their own without being ordered from advisors. Asking straight what they want to do then starting finding materials by themselves. This kind of a person is someone who will be successful."

(An advisor of the project 2/ October 2nd 2017)

From the comments above, the advisor's comment is about the successful group in national stage and international stage. It is because they have their passion on science and can see through a problem occurring on their own backyards then try to find the way to eliminate the problem by using scientific methods. They are ambitious to acquire more knowledge, intelligent and stand against the obstacles during the procedures of their project. In the end, they are very successful in their science project and their group is the great example for other students in school.

School directors see the importance of science projects Scientific methods are the procedures that require the systematic thinking process. They are reasonable, provable and believable. Scientific methods are the daily life foundation for everyone. They are things students have learnt since they were young. Scientific methods have integrated other subjects' contents which advisors have to apply their various teaching techniques. Therefore, the school direct has seen the importance of them. This is considered as the first significant step to do science projects inside school. 
"Scientific methods help figure out problems that can be applied to use in every subject. Hence, skills of proceeding Scientific methods are important to apply all subjects together."

(School director/ October 3rd 2017)

Supportive directors if advisors and students are able to develop their outstanding projects but have no support from their directors, the projects will not be complete and successful as they would encounter the insufficient budget obstacle and traveling obstacle which would impede the opportunities to reach to the competitive rounds. Therefore, school directors should encourage the science camp which will help improve skills in making science projects or field trips to motivate both advisors and students. They should prepare budgets by seeking for helps from other schools in school network so that school directors will be able to provide money for equipment, materials, and traveling fees etc.

"We ask school committee, Alumni association... especially, for science projects we are able to raise some funds from school, school committee, and alumni because we need to share the money paid as every sector is involved with school's fame."

(School director/ October 3rd 2017)

Supports from students' parents for junior and senior school students, when they encounter some pressure, they will feel stressed easily. So, the encouragement from their parents is very important to them because it will motivate and drive them to overcome their obstacles. After they have overcome the obstacles, parents still support them in term of traveling between school and places. Also, providing materials needed.

"Mom always encourages me... keeps telling me that everything will be fine. If this work isn't good enough, I can always keep improving it. Because of her, I want to keep developing my work."

(Student from group $1 /$ October 2nd 2017)

3.2 Mechanism drives to the success besides the conditions of people to succeed. There is mechanism ankle that motivates the projects to be successful as the researcher has discovered as following

Teamwork Working as a team is crucial for doing science projects for both advisor teams and student teams. Advisors have to plan the systematic working process; help one another thinking the ways out of problems, purpose the fields of projects in which they are professional, and purpose different thoughts with causing argument among them. Advisors have to unite themselves and set the same goals. For student teams, besides be able to surround with teacher society, they need to plan the projects neatly following skills and interests of teammates and themselves.

"A team is very important. There should not be a solo advisor because it requires advisors who are skillful in their study fields and requires several fields. Each person have different perspectives that need to be exchanged. If we can find the center for all perspectives, we can enhance our students' project levels. However, people in the same teams need to go on the same directions without any arguments."

(An advisor of the project 1/ August 19th 2017)

Creation of successful example In school, there should be one outstandingly successful example for the entire school. It can be from advisors trying to push one successful group of students who love doing their Science project until they can achieve national or international competition rounds. After that students also feel interested to become a successful example group. Everything follows the old system and is easily to comprehend. Advisors will be accepted by their students, school director, and parents more.

"The First successful has to go through some difficulties because how to start is hard. How to make students become idols for the school is hard. They need to be very motivated....such as certificates for their portfolios for their entrances of universities. Then, they start from the small competition's stage. If they can still go on, we need to keep pushing them until we can get one outstanding student... The next success will be easier."

(An advisor of the project 1/ August 19th 2017) 


\section{Conclusion and Discussion}

To make the science projects become successful, it needs a lot of participants who support and drive the projects to achieve the set goals. If the schools have some supportive people, but lack of motivation to succeed the goals, those science projects will not reach its goals. Conclusions is separated into 4 points related to the success of science projects' procedures as following

First point is about advisors from the research, advisors/advisors are the importantly initial persons for the start of science projects. They push, motivate, give advices, and solve problem relevant to the research of Pradit and Naphatsorn Laonet (2009) Teachers have their roles in advising their students by helping them think, plan and design the experiment, set up the variables, design the checking process or design the inventions, researching the information and knowledge related with the equipment and procedures of the projects, taking care and following with the experiments, going out for surveying and making the inventions closely with students, and also looking after the writing report procedures.

Second point is about students the research has found that one of conditions drive to the success is students who are ambitious, interested in problems occurred around them. When they know their outstanding thesis topics from all topics in their community. They are very responsible to their work. They don't let the projects affect their other subjects. They can adjust themselves well to work with advisors and their teammates. All mentioned are considered as very good qualifications.

Third point is about supports from relevant people as school director has seen the importance of scientific methods. The supports from external network has reached to support Science Math and Environment classes. It has created opportunities for both advisors and students. School director has supported the budget fully by gathering budget from school network and providing sufficiently. Supports from the school director drive the success of the school as said by Pitak Chiangnok (1997) has stated "The roles of school directors as following. Support teachers and students in procedures of the science projects by providing them the suitable budgets, and tools. Understand that they need to support teacher and student need to seek out the knowledge outside classes and spend some extra times outside. So, the school directors should support them and make them spend time outside efficiently".

Forth point is about mechanism driving the success from the research, it has found that the initiation of the science projects is relevant to everyone in the team science projects in same direction of perspectives. They have planed the annual procedures in order to guide how to proceed the work in each step of the academic year. If the projects can get through to further rounds, budget is enough or not and where else they should raise the funds. Besides, advisors need to know the aspect of making good science projects and how to acquire the prizes such as they have to relate to problems of society and daily lives - how to solve problems and create benefits for them. The science projects have to be practical and can be applied to use for reality. If they can do all these, their science projects will win committeemen's hearts and receive the prizes.

\section{Suggestion}

\subsection{Suggestion in Principle}

What the research has found and thought that they are necessary for the successful science projects are before, during and after procedures of the science projects which are advised in principle way in each sectors as following

a.) Before the procedures, advisors should use the outstanding points of school's area in order to have their students seek for their thesis topics related to their community. And carefully design the experiment.

b.) During the procedures, advisors should take care the students' projects' experiment all along so that they can advise their students during the experiments and solve the problems occurred immediately which students should try their best, be patient and be responsible to their jobs.

c.) After the procedures, advisors and relevant teammates should prepare students to be ready for the presentations. 
Conditions that drive them succeed are people who are important to the projects such as advisors, students, and other relevant people. The recommendations for all conditions in order to improve more are

a.) Advisors needs to give themselves chances to exchange some experiences which successful advisors or visit the successful projects and always study more for additional knowledge to expand their perspectives towards things.

b.) Students, during their procedures, they have to encounter some problems and obstacles that happen in each step. Therefore, they need to try their best and bear with those things. Be calm to find the ways to figure out things so that they can become successful which will not happen to them since the first step. They need to keep going until they succeed.

c.) Supports, if the school director or other external supports see the importance of scientific procedures, they should have some policies in term of finding more equipment, materials, places, budgets to encourage advisors and students' performances.

From the research, teamwork and successful example are mechanisms that drive science projects to achieve their success. Therefore, the school director and science department's advisors should help one another to plan the annually working procedures and set up the teams for science projects to proceed the projects more systematically, quickly and qualifiedly as if they want to create more successful examples following the first group that succeeds. Then, using the successful group to motivate other students in next generations or for new advisors in order to remain the working platform but improve more significant performance.

\subsection{Suggestions for the Next Research.}

a.) Study the procedures of making science projects that have won the prizes from the international contest stage.

b.) Study the process of doing a math project or an invention project.

\section{Acknowledgements}

First, I would like to thank my advisor Assistant professor Dr.Narisara Peungposop and Dr.Wilailak Langka for advisement that help me successfully complete my research. In addition, I would also like to express my special thanks to The Graduate School of Srinakharinwirot University for supporting this research presentation.

\section{References}

[1] Institute for the Promotion of Teaching, Science and Technology, science activities exercises s.017 scientific project and junior high school life quality, Bangkok, Thailand, 1999, pp.8.

[2] Pitak Chiangnok, "Factors Relating to the Science Project Conducted by Lower Secondary School Students in Schools under the department of Genaral Education, Nakhon Ratchasima Province." M.ED. thesis, The Graduate School of Chiangmai., Chiangmai Univ., Chiangmai, Thailand,1997.

[3] Pradit and Naphatsorn Laonet, The Science Project, Bangkok, Thailand, (2009)

[4] Sukda Satapornwajana, "Studying of the procedures of creating the winning science projects of Senior high schools from The Science Society of Thailand under the Patronage of His Majesty the King.” M.ED. thesis, Dept. Supervision and Curriculum., Chulalongkorn Univ., Bangkok, Thailand, 1997.

[5] Sukunlaya Khumphet, "A study of Condition and Problem in science project and junior high school, Phetchaburi Province.” M.S. thesis, The Graduate School of King mongkut's Institute of Technology Ladkarabang. KMITL Univ., Bangkok, Thailand, 2000.

[6] The Science Society of Thailand under the Patronage of His Majesty the King, Youth Activities Guide, Bangkok, Thailand, 2014, p. 38. 